Original Contribution

\title{
IN SEARCH OF NEW MODELS TO GUIDE THE PRACTICAL TRAINING OF SPECIAL PEDAGOGY STUDENTS
}

\author{
V. Kacarska, Zh. Stoykova* \\ Faculty of Education, Trakia University, Stara Zagora, Bulgaria
}

\begin{abstract}
This study is focused on the practical training of students in the field of special pedagogy and the factors that can lead to its improvement. It demonstrates the need for active involvement of the academic staff in the process of practical training as a prerequisite for improved quality. Another important determinant of the good practical training of students appears to be the application of modern practices resulting in enhanced motivation for achievement.
\end{abstract}

Key words: factors of practical training, special pedagogy, application of modern practices

\section{INTRODUCTION}

It is vitally important to improve the university training of students across all fields of education and especially in the field of special education. On the one hand, society needs more and more well-trained specialists, and on the other hand - certain resources connected with practical training remain largely unused. It would not be an overstatement to say that practical training nowadays requires a whole new conceptual framework.

The goal of this research is to explore some of the aforementioned unused resources, namely the human resources, and to incorporate them into the newly emerging conceptual framework.

Special education, just like every other scientific field of social significance, is in a state of constant development in terms of the three basic and interconnected aspects of theory, practice and scientific research. Many different authors have emphasized the connection between those three aspects of special education. Iv. Karagyozov (1) explores the idea of the mutual connection between them and underlines the need to regard them all as equally important. D. Levterova Gadzhalova (2), R. Trashliev, E. Evgenieva (3) and many other authors support similar notions.

*Correspondence to: Prof. Zh. Stoykova, PhD, Faculty of Education, Trakia University, Stara Zagora,Bulgaria,jj_stoykova@yahoo.com
It would be difficult to contest the significance of each of the three aspects of special education- theory, practice and scientific research, as well as the mutual connections and equality between them. Thus, the practical training of students can be viewed separately only to some extent.

It is self-evident that a young specialist, who only has at his disposal a good theoretical background but lacks professional competence owing to insufficient practical training, cannot be optimally useful to society and even to himself. That is why; the issue of raising the quality of practical training is often brought up by government agencies and non-governmental organizations, with some of the most vocal supporters of this effort being employers and the families of children and students with special educational needs. Many authors, such as Vl. Radulov (4), M. Tsvetkova (5) and N. Nazarova, have explored the topic of the quality of practical training and the means to increase it. M. Tsvetkova (5, p.95) emphasizes the usefulness of the individualized practical training of specialists working with deaf-mute people.

Nowadays, practicing the teaching profession requires certain personal qualities and traits. $R$. Trashliev and E. Evgenieva (3) focus on the need to develop a personal teaching style that includes certain idiosyncrasies, as well as, a personal way of choosing work approaches, principles and methods, i.e. a combination of good theoretical and practical preparation. It is 
KACARSKA V., et al.

especially important to adequately apply and utilize the acquired knowledge and skills in certain real-life situations. Some of these situations might have never been discussed or even imagined. In these situations, the interaction between children with special educational needs, their parents and families, the teaching specialists and the students is extremely complex.

\section{CONCEPT AND METHODOLOGY}

From the perspective of Individual Psychology, the development of the professional characteristics of the educator and the special needs pedagogue in particular can be connected with Alfred Adler's concept of the development of social interest. Social interest is defined as community feeling of care for other people, empathy, and willingness to cooperate and provide help. (7) These are qualities that should be immanent in the psychological profile of the special needs pedagogue.

Based on the scientific literature on the topic of social interest, our team formulated the hypothesis that students preparing for professions in the field of education mostly exhibit average and above-average levels of social interest. The research we conducted was focused on measuring the social interest of students in an academic setting. The goal was to explore the possible correlation between the level of social interest and the choice of professional orientation. This effort is based on the understanding that young people's pursuit of professions in the field of education (including special education) is not accidental but instead is based on their pronounced interest in the problems of other people - the children, the elderly and the disabled. The subjects of the research were 167 students majoring in "Preschool and elementary school pedagogy", "Social pedagogy" and "Special pedagogy". 132 of the students were pursuing Bachelor's degrees, while 35 students were pursuing Master's degrees. The research was conducted between 2009 and 2011 at the Faculty of Education at Trakia University in Stara Zagora. Participation in the research was strictly voluntary. The confidentiality of the individual results was guaranteed and only the summarized results are presented here.

This research uses the Social Interest Scale developed by J. Crandall (Crandall* SIS Crandall, 1975; 1981) $(8 ; 9)$.

\section{RESULTS AND DISCUSSION}

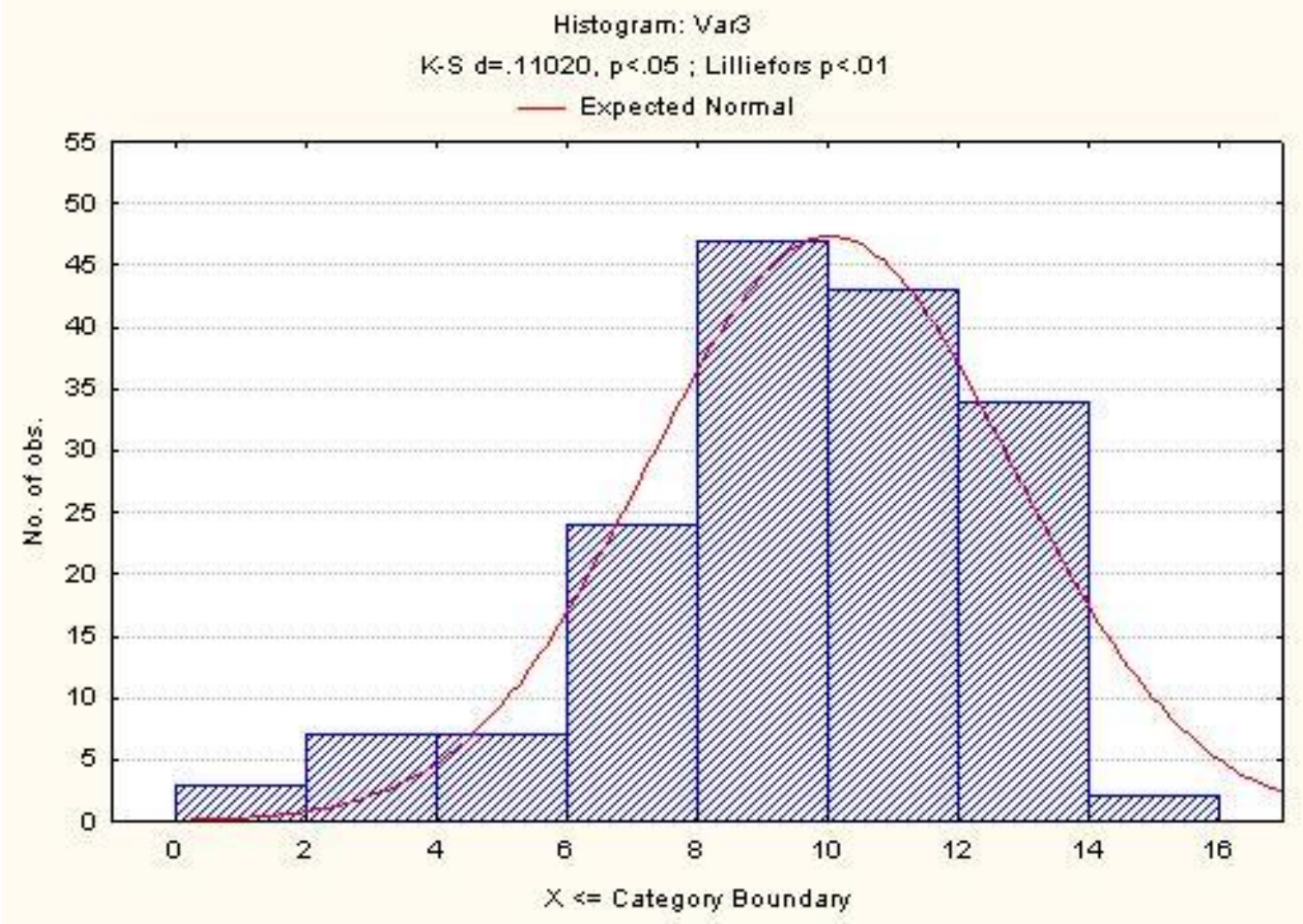

Figure 1. Distribution of the respondents' results on the social Interest Scale 
KACARSKA V., et al.

In Figure 1 Var3 are the values of the respondents' social interest.

The mean of the respondents' results on the Social Interest Scale has the following characteristics:

Mean $=10,04192 ; \min =2 ; \max =15 ; \operatorname{Std} \operatorname{Dev}=$ 2.816375; $\mathrm{N}=167$

In comparison with the standard quality norms of social interest the mean value (Xav. = 10.04) lies at the higher end of the average level of social interest, in the range between 7 and 11 points.

This demonstrates a tendency toward increased level of social interest among the students in all pedagogical majors pursuing Bachelor's and Master's degrees.

The results of the research allow us to draw the main conclusion that the level of social interest, which is formed during childhood and adolescence, affects the individual's professional orientation. Individuals that exhibit above-average or high levels of social interest are more likely to pursue a career in the helping or socially-oriented professions, including the profession of the special needs pedagogue.

The teaching profession has always been viewed as extremely complex, but many authors believe that nowadays its complexity is increasing further. It is no accident that this profession has its own statute and a dynamically changing status dependent on the ever-changing social relations.

The increasing role of the teaching profession as a socially beneficial activity, including its role for children with special educational needs, requires a broad discussion of both general and very specific issues.

One of those issues is the practical training of students, which is designed to prepare them to practice the teaching profession and in particular to work as "special needs teachers". The development of the capability to practice this profession is a continuous process. In retrospect, the emergence of the motivation to become a teacher can be traced back to early childhood when an encounter with a good teacher can make young children begin to dream of becoming teachers themselves, with some of their games revolving around scenarios of "playing the roles of teachers and students".

For some of them, this childhood dream becomes reality and they enroll in pedagogy university programs. The interest in studying special pedagogy as the person's chosen professional path is most commonly formed and developed later in life. The potential increase of this interest is, to a significant degree, determined by the student's practical preparation.

The different types of practice- practical observation, teacher observation, teaching practice and pre-graduate internships, play an important role in accomplishing the primary goal of practical training. All the aforementioned forms of training, while retaining at least to some extent their own distinct positions, enter into relations with each other and combine to form the indivisible unity of practical preparation. Each of the different types of practice presented above has its own relatively independent place and role, but it should rather be regarded as connected with and determined by all the others as part of the integrated and continuous process of student training.

In their practical training, the special education university students encounter children and students with special educational needs in their first visits to different structures and practices. They also meet members of the teams working with the children - the special education teachers, occupational therapists, speech therapists and others. All of this plays a vital role in their practical and psychological preparation. During those first meetings with children with special educational needs in different situations, and especially with the most severe cases, some students also need the encouragement of sufficiently experienced and competent teachers and psychologists. For some of the aspiring special needs teachers, those first encounters are difficult to bear and in some cases they go on to graduate from university but then refuse to work as special needs teachers. Even though such students are a small minority, it is necessary for experienced specialists in pedagogy and psychology to be present at those first meetings.

At the same time, the development of the practical skills and personal qualities and characteristics that a special education teacher needs, is entrusted completely to the teaching specialists and the assistant professors. They bear almost the entire responsibility for the complex process of preparing students for practicing the profession of special needs teachers. Both the complex process of adaptation to different and constantly changing conditions that the students are not familiar 
with, and the individual process of adaptation to the new conditions which every person must undergo require support, encouragement and assistance - something that the teaching specialists and assistant professors are not capable of providing on their own. It is necessary for associate and full professors to participate (become involved) as they are the most experienced members of the team preparing the students majoring in special education. The current legislation requires associate and full professors to conduct the state practical examinations. However, the practical training of students is almost completely entrusted to the teaching specialists and assistant professors, while the associate and full professors are in charge of the theoretical training. This disrupts the teambased model of student training and leads to disparities in the quality of this training.

In addition to that, the assistant professors cannot be present simultaneously in all the practicing groups because of the nature of working in the inherently small groups, school classes, resources assistance offices or other practices, which leads to students receiving only the help of the teaching specialists during most of their practical training. This is not adequate preparation for the individual student and in some cases it could also be detrimental to the children (individuals) with special educational needs, their parents and families. Often, decisions in a specific situation have to be made with limited time available and in such cases the assistance of an experienced academic faculty member can help prevent erroneous decisions.

In the complex process of practical preparation, which involves diagnosing disorders, formulating special educational needs, determining the strengths and weaknesses of children and adults, choosing work approaches, content and methods, as well as solving other important matters, once more we are faced with the issue of the need to have the whole team present during this process not just a part of the team. It is well known that in their practical training, students usually reproduce the actions and behavior of the teaching specialists. Most of them find it difficult to form their "own style" and this process could be stimulated with the help of academic instructors.

The assumption that students who have a good theoretical foundation in the field of special pedagogy will automatically be able to prepare optimally in practical terms is problematic. Even if their theoretical foundation is sound (there could be gaps in some students' theoretical knowledge), it is necessary to transform it into specific skills. R. Trashliev and E. Evgenieva (3, p.20) point out that such a transformation can only occur "in the process of the practical preparation itself". This optimal process of transformation also requires support and competent assistance provided by the entire team to the students.

A team that functions as a unified whole could be better aware of the environment and might find it easier to determine how to remedy problems with the theoretical preparation in such situations, including by means of additional consultations and advising. The threat of underestimating the gaps in the preparation or the inability to transform theoretical preparation into specific practical skills and use them in the development of one's "own style" in the teaching profession, supports the thesis that practical training needs to be performed by the entire team, which includes highly competent associate or full professors, who also possess sufficient practical experience.

Without underestimating the theoretical and practical preparation of teaching specialists and young assistant professors, it should be noted that concrete situations can be defined as "repetitive" or "unrepeatable". (R. Trashliev, E. Evgenieva, 3, p.26). Practical skills and habits are known to be mostly connected with the former type of situations. The unrepeatable situations - problematic and especially critical situations, can pose significant difficulties to the student. In those situations, the support and competent help of the entire team would be crucial. Critical situations can arise for a variety of reasons. Some of those reasons could be connected not only with the child himself (for instance, in case of declining health, auto aggressive behavior in an autistic child, manifestations of negative attitude as unmotivated resistance against the presence or demands of the student who is unfamiliar to the child, negative displays stemming from "pampering" or vice versa - from the child's needs being neglected in the family environment, and many others), but could also be linked with insufficient experience of the students in practice. That could greatly discourage them and affect their desire to practice this socially significant, but very complex profession. This influence might even go beyond the professional sphere and affect the individual's personal life. Once more, the help of experienced professionals working in a team would play a vital role in overcoming 
KACARSKA V., et al.

such situations and eliminating the negative influences.

During school year 2012-2013, a study was conducted among seniors majoring in social pedagogy as part of the scientific project titled "Communication and social reciprocity". In this study, $80 \%$ of the respondents indicated that social reciprocity in academic training can be achieved by incorporating more hours dedicated to practical training and illustration of the application of theoretical knowledge. Because the question was focused on the amount of training hours, in their answer the students expressed the desire to see an increase in the number of hours. However, based on our concrete observations, it seems that there is enough evidence to put forth the hypothesis that it is not merely quantity (which is indeed important) that answers the students' needs, but possibly support and competent assistance as well. Those additions would help in the accumulation of experience in handling difficult situations, both problematic and critical ones, and in changing their status from "unrepeatable" to "repetitive" situations. Of course, that could only work to some degree, because it is impossible for every single "unrepeatable" situation to be characterized later on as "repetitive", even given sufficient experience. Moreover, situations are not static but dynamically changing. This does not concern so much the nature of the situation itself, but mostly the accumulation of experience, its rationalization, summarization and subsequent utilization. If students are provided with the necessary support and assistance, they will learn to analyze situations and use all their resources to practice their profession independently in the future, instead of regarding such situations as hopeless or irresolvable.

The summarization of the experience acquired during practical training is another problem for students. It is also of utmost importance. This summarization is comparable with the conceptualization of theoretical knowledge - a process that only begins, but does not end with the theoretical preparation of students. The practical preparation of students can be seen in a similar light. It cannot be regarded as accumulation of experience based on specific situations - more complex or less complex, repetitive or unrepeatable by nature. The analysis of those situations and their summarization using theoretical knowledge obviously determine the readiness of student to practice the profession of special needs teacher. It appears self-evident that the participation of experienced psychologists and pedagogues in the team preparing the student is of utmost importance in this complex process.

\section{CONCLUSIONS}

In summary, the practical preparation of students in the field of special education is extremely important. It can be analyzed within the context of the overall student training. It is one of the three inseparably interconnected aspects of special education- theory, practice and scientific research. All of this necessitates the search for a new model to guide the practical training of students, involving the participation of experienced psychologists and pedagogues, currently almost exclusively focused on theoretical preparation, in the teams working with the student.

This new guidance model was partially approbated during last year's pre-graduate internship of students majoring in special pedagogy and hearing-and-speech rehabilitation in particular. The first efforts in this direction have yielded encouraging results.

\section{REFERENCES}

1. Karagyozov, Iv., V. Katsarska, Resursna (spetsialna) pedagogika. V. T, 2008.

2. Gadzhalova - Levterova, D. Aktualni problemi na spetsialnoto obrazovanie. Pl., 2002.

3. Trashliev, R., E. Evgenieva. Prakticheska podgotovka. S., 2008.

4. Radulov, Vl. Detsata sas spetsialni obrazovatelni nuzhdi $\mathrm{v}$ uchilishteto $\mathrm{i} \mathrm{v}$ obshtestvoto. DARS, Burgas, 2007.

5. Tsvetkova, M. Obuchenie na slyapogluhi detsa i yunoshi. SU, 2004

6. Nazarova, N. M., red. Spetsialnaya pedaegogika. M. AKADEMA, 2000.

7. Adler. A., Social Interest: A Challenge to Mankind. Capricorn Books, New York, 1964

8. Crandall, J. E., Theory and measurement of social interest: Empirical tests of Alfred Adler's concept. New York: Columbia University Press, 1981

9. Crandall, J. E., A Scale of Social Interest. Journal of Individual Psychology, 31,187 195,1975 